\title{
Comparison of selenophene and thienothiophene incorporation into pentacyclic lactam-based conjugated polymers for organic solar cells
}

\author{
Renee Kroon, Armantas Melianas, Wenliu Zhuang, Jonas Bergqvist, Amaia Diaz de Zerio \\ Mendaza, Timothy T. Steckler, Liyang Yu, Siobhan J. Bradley, Chiara Musumeci, Desta \\ Gedefaw, Thomas Nann, Aram Amassian, Christian Muller, Olle Inganäs and Mats R. \\ Andersson
}

\section{Linköping University Post Print}

\section{Tweet}

N.B.: When citing this work, cite the original article.

Original Publication:

Renee Kroon, Armantas Melianas, Wenliu Zhuang, Jonas Bergqvist, Amaia Diaz de Zerio Mendaza, Timothy T. Steckler, Liyang Yu, Siobhan J. Bradley, Chiara Musumeci, Desta Gedefaw, Thomas Nann, Aram Amassian, Christian Muller, Olle Inganäs and Mats R. Andersson, Comparison of selenophene and thienothiophene incorporation into pentacyclic lactam-based conjugated polymers for organic solar cells, 2015, Polymer Chemistry, (6), 42, $7402-7409$.

http://dx.doi.org/10.1039/c5py01245g

Copyright: Royal Society of Chemistry

http://www.rsc.org/

Postprint available at: Linköping University Electronic Press

http://urn.kb.se/resolve?urn=urn:nbn:se:liu:diva-122675 


\section{Journal Name}

\section{ARTICLE}

\section{Comparison of selenophene and thienothiophene incorporation into pentacyclic lactam-based conjugated polymers for organic solar cells}

Received 00th January 20xx, Accepted 00th January 20xx

DOI: $10.1039 / x 0 x \times 00000 x$

www.rsc.org/
Renee Kroon ${ }^{\mathrm{a}, \mathrm{c}^{*+}}$, Armantas Melianas ${ }^{\mathrm{b}^{*+}}$, Wenliu Zhuang ${ }^{\mathrm{c}}$, Jonas Bergqvist ${ }^{\mathrm{b}}$, Amaia Diaz de Zerio Mendazac, Timothy T. Steckler ${ }^{c}$, Liyang Yud, Siobhan J. Bradley ${ }^{a}$, Chiara Musumeci ${ }^{b}$, Desta Gedefaw $^{c}$, Thomas Nann ${ }^{\mathrm{a}}$, Aram Amassian ${ }^{\mathrm{d}}$, Christian Müller ${ }^{\mathrm{c}}$, Olle Inganäs ${ }^{\mathrm{b}^{*}}$ and Mats R. Andersson ${ }^{a, c^{*}}$

In this work, we compare the effect of incorporating selenophene versus thienothiophene spacers into pentacyclic lactambased conjugated polymers for organic solar cells. The two cyclic lactam-based copolymers were obtained via a new synthetic method for the lactam moiety. Selenophene incorporation results in a broader and red-shifted optical absorption while retaining a deep highest occupied molecular orbital level, whereas thienothienophene incorporation results in a blueshifted optical absorption. Additionally, grazing-incidence wide angle X-ray scattering data indicates edge- and face-on solid state order for the selenophene-based polymer as compared to the thienothiophene-based polymer, which orders predominantly edge-on with respect to the substrate. In polymer: $\mathrm{PC} \mathrm{7}_{71} \mathrm{BM}$ bulk heterojunction solar cells both materials show a similar open-circuit voltage of $\sim 0.80-0.84 \mathrm{~V}$, however the selenophene-based polymer displays a higher fill factor of $\sim 0.70$ vs. 0.65. This is due to the partial face-on backbone orientation of the selenophene-based polymer, leading to a higher hole mobility, as confirmed by single-carrier diode measurements, and a concomitantly higher fill factor. Combined with improved spectral coverage of the selenophene-based polymer, as confirmed by quantum efficiency experiments, it offers a larger short-circuit current density of $\sim 12 \mathrm{~mA} / \mathrm{cm}^{-2}$. Despite the relatively low molecular weight of both materials, a very robust power conversion efficiency $\sim 7 \%$ is achieved for the selenophene-based polymer, while the thienothiophene-based polymer demonstrates only a moderate maximum PCE of $5.5 \%$. Hence, the favorable effects of selenophene incorporation on the photovoltaic performance of pentacyclic lactam-based conjugated polymers are clearly demonstrated

\section{Introduction}

The development of renewable energy technologies that answer the $1 \mathrm{GW} /$ day global energy increase is one of the great challenges of present time. ${ }^{1}$ One technology to meet this challenge is the organic solar cell (OSC), combining cheap and high-throughput manufacturing with high power-conversion efficiencies (PCE) over $10 \%,^{2-5}$ production of large area solar modules 6 and lifetimes of up to 7 years. ${ }^{7}$ The best performing OSCs often utilize an interpenetrating network of a conjugated polymer as the primary light-harvesting and hole transporting

\footnotetext{
a. Ian Wark Research Institute, University of South Australia, Mawson Lakes Boulevard, Adelaide, SA 5095 (Australia).

b. Department of Physics, Chemistry and Biology, Linköping University, 58183 Linköping (Sweden)

c. Department of Chemistry and Chemical Engineering, Chalmers University of Technology, 41296, Göteborg (Sweden)

d. Material Science and Engineering Program, Division of Physical Science and Engineering, King Abdullah University of Science and Technology, Thuwal 23955 6900, Saudi Arabia

${ }^{+}$These authors contributed equally to this work

Electronic Supplementary Information (ESI) available: [Experimental details, synthetic procedures, electrochemistry, TGA, GIWAXS, AFM and photovoltaic device data]. See DOI: 10.1039/x0xx00000x
}

material and a fullerene derivative, usually $\mathrm{PC}_{61} \mathrm{BM}$ or $\mathrm{PC}_{71} \mathrm{BM}$, the secondary light-harvesting material that is essential for exciton dissociation and electron transport. As these fullerenes are ubiquitous, it is the energy levels of the conjugated polymers, i.e. the highest occupied molecular orbital (HOMO) and the lowest unoccupied molecular orbital (LUMO), that are usually modulated in accordance to the energy levels of the fullerene.

Therefore, the past few years have seen a surge of material designs for conjugated polymers. Some of these stand out due to their favorable material properties, particularly diketopyrrolopyrrole ${ }^{8,9}$ or perylene diimide $^{10}$, and polymers containing large fused backbone moieties, e.g. various indacenodithiophene derivatives ${ }^{11-14}$ or other large extended fused systems ${ }^{15-19}$. Their molecular design promotes inter-chain stacking via polar groups and/or $\pi-\pi$ interactions resulting in improved solid-state order that enables efficient charge separation and transport. Additionally, this design allows for deposition of thick active layers which is essential for large-area processing and also improves phase purity, which potentially reduces recombination. ${ }^{17,18}$ Furthermore, extended fused moieties in the polymer backbone may improve charge separation. ${ }^{20}$ This allows for a minimal LUMO 
offset that ensures a high open-circuit voltage $\left(\mathrm{V}_{\mathrm{oc}}\right)$ and also a high short-circuit current density $\left(\mathrm{J}_{\mathrm{sc}}\right)$ due the smaller bandgap and thus a wider absorption spectrum. Normally, a minimal LUMO $_{\text {polymer - LUMOPCBM offset would constitute a loss }}$ mechanism, either via reduced exciton separation efficiency ${ }^{21}$ or aggravated recombination. ${ }^{22,23}$

One building block that combines many of the aforementioned desirable properties is thieno[ $\left[2^{\prime}, 3^{\prime}: 5,6\right]$ pyrido[3,4-g]thieno[3,2c]isoquinoline-5,11(4H,10H)-dione (TPTI). TPTI is a pentacyclic lactam ring which, when copolymerized with thiophene, yields a small bandgap and semi-crystalline conjugated polymer displaying considerable solid-state order in films. When blended with $\mathrm{PC}_{71} \mathrm{BM}$ a PCE of $7.8 \%$ has been reached. ${ }^{24}$ However, reported derivatives of the original TPTI polymer that have incorporated various donor units (thienothiophene (TT), bithiophene (BT), benzodithiophene (BDT) and dithienopyrrole (DTP)) were never able to simultaneously achieve both a redshifted absorption and a high $\mathrm{V}_{\mathrm{oc}}$ of the corresponding photovoltaic device. ${ }^{25,} 26$ Following several works, most notably by Heeney et al,27-31 a selenophene donor could however be employed to combine a redshifted optical absorption while retaining a high $\mathrm{V}_{\mathrm{oc}}{ }^{32}$ Although Se-TPTI has been shown to have a redshifted optical absorption (absorption onset $=710 \mathrm{~nm}$ ), despite the improved spectral coverage, bulk heterojunction solar cells based on Se-TPTI:PC ${ }_{71} \mathrm{BM}$ still underperform (PCE $6 \%$ ) compared to some other well-performing TPTI derivatives. For example, BHJ OSC's based on TT-TPTI and BT-TPTI achieved a PCE of $\sim 5.8 \%$ and $\sim 6.8 \%$ respectively, whilst having a similar $\mathrm{V}_{\text {oc }}$ to Se-TPTI but larger bandgaps, i.e. lesser spectral coverage. The exact reason of why Se-TPTI:PC ${ }_{71} \mathrm{BM}$ would underperform is not clear.

Therefore, we investigate the effects of selenophene incorporation into TPTI in more detail. We report a new synthesis route for the TPTI unit and compare material properties of the resulting Se-TPTI copolymer (designated P2) with the previously reported TT-TPTI copolymer (designated P1) as our reference, as it provides a similar open-circuit voltage but a larger bandgap. We find that the incorporation of selenophene indeed retains a deep HOMO level and a simultaneous improvement in spectral coverage. Atomic force microscopy (AFM), transmission electron microscopy (TEM) and photoluminescence (PL) quenching indicate similar polymer: $\mathrm{PC}_{71} \mathrm{BM}$ blend nanostructures, while grazing incidence wide-angle $x$-ray scattering (GIWAXS) reveals edge and face-on backbone orientations for Se-TPTI while TT-TPTI orients predominantly edge-on with respect to the substrate. The similar $V_{o c}$ in both blend systems is investigated by Fouriertransform photocurrent spectroscopy (FTPS) and electroluminescence (EL) measurements and is shown to originate due to the similar energy of the charge-transfer (CT) state and similar radiative and non-radiative losses. From external- and internal-quantum efficiency (EQE and IQE) measurements we then conclude that the improved $\mathrm{J}_{\mathrm{sc}}$ of $\mathrm{BHJ}$ OSC based on Se-TPTI:PC ${ }_{71} \mathrm{BM}$ can be attributed to the increase in optical absorption and its partial face-on backbone orientation. Despite the low molecular weight of Se-TPTI, a promising PCE of $7.1 \%$ was achieved as compared to the previously reported $\sim 6 \%$. The higher PCE places Se-TPTI among the top selenophene-based conjugated donor polymers and reflects the true potential of the selenophene incorporation into TPTI-based copolymers.

\section{Results and discussion}

\section{Material synthesis}

To obtain the TPTI core unit, an experimental procedure as reported by Tour et al. was modified (Scheme 1). ${ }^{33}$ Initially, a Stille coupling of tert-butyl 2-(trimethylstannyl)thiophen-3-
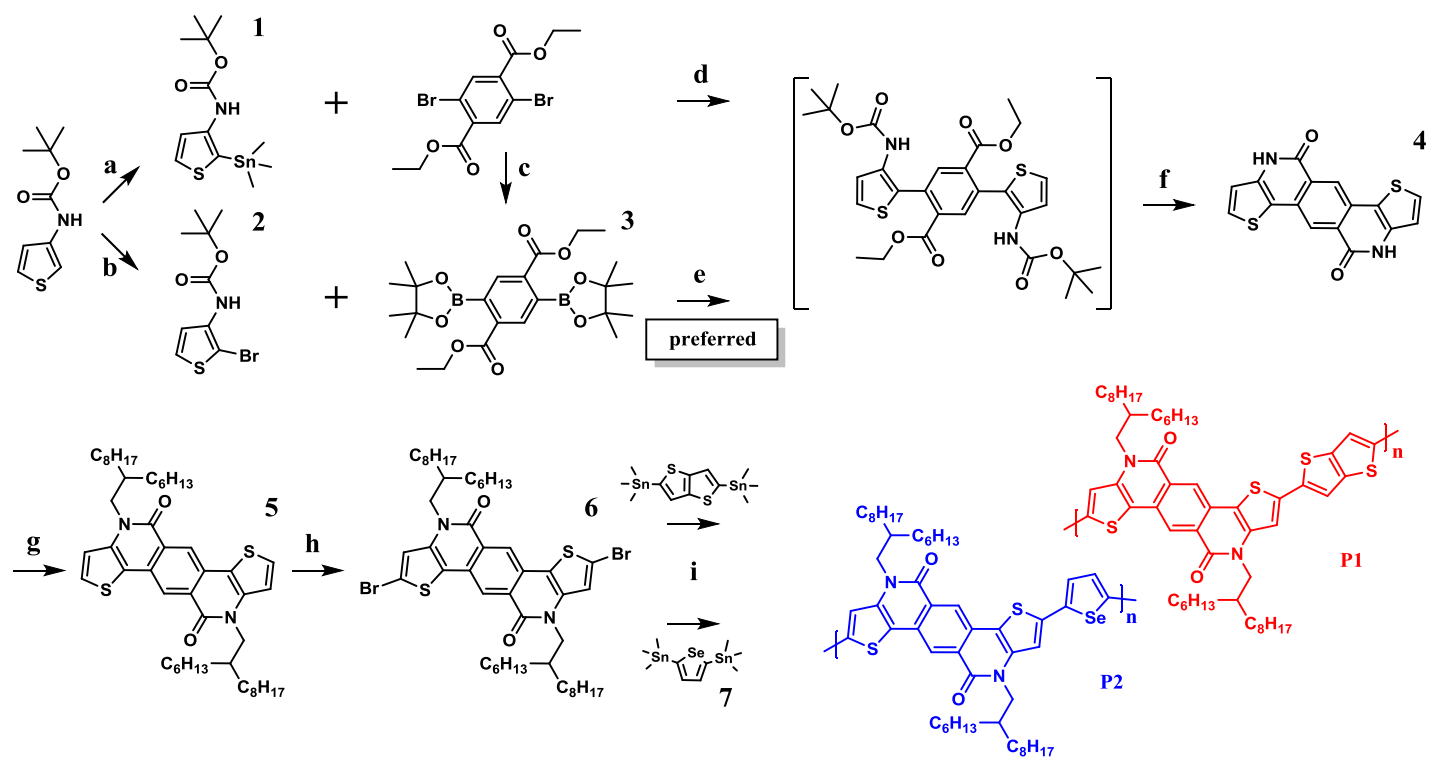

Scheme 1 | Synthetic routes towards TPTI, P1 and P2. a) LDA, Me $\left.\mathrm{SnCl}_{3} \mathrm{THF},-78{ }^{\circ} \mathrm{C}, \mathrm{b}\right) \mathrm{NBS}, \mathrm{CCl}_{4}$, reflux. c) bis(pinacolatodiboron), $\mathrm{PdCl}(\mathrm{dppf})_{2}, \mathrm{KOAc}, \mathrm{DMF}, 90{ }^{\circ} \mathrm{C}$. d) $\mathrm{Pd}_{2}(\mathrm{dba})_{3}, \mathrm{P}\left(o-\mathrm{Tol}_{3}, \mathrm{THF}, 70^{\circ} \mathrm{C}\right.$. e) $\mathrm{Pd}_{2}(\mathrm{dba})_{3}, \mathrm{P}(\mathrm{o}-\mathrm{Tol})_{3}$, dioxane, $\mathrm{NaHCO}_{3}(\mathrm{aq}), 90^{\circ} \mathrm{C}$. f) DCM, TFA (route d) $6 \mathrm{M} \mathrm{HCl}, \mathrm{RT}$ (route e). g) 2-hexyldecylbromide, $\mathrm{K}_{2} \mathrm{CO} \mathrm{O}_{3}, \mathrm{DMF}, 90{ }^{\circ} \mathrm{C}$. h) NBS, $\mathrm{CHCl}_{3}, \mathrm{DMF}$. i) $\mathrm{Pd}_{2}(\mathrm{dba})_{3}, \mathrm{P}(\mathrm{o}-\mathrm{Tol})_{3}$, toluene, $90^{\circ} \mathrm{C}$. 
ylcarbamate (1) with diethyl 2,5-dibromoterephthalate was performed, resulting in poor yields (16\%) of the 5-fused product after deprotection. Poor yields were attributed to the limited stability of the stannyl compound since part of the N-Boc thiophene was recovered after reaction. Therefore, we employed Suzuki conditions in an attempt to obtain the desired lactam 4. After synthesis of the respective bromide (2) and boronic ester derivative (3), the Suzuki reaction e was performed during which a dark yellow precipitate was formed. This observation suggests that intramolecular cyclization of the product already occurs during the Suzuki coupling reaction, as was also observed in aforementioned work of Tour et al. To ensure complete deprotection and subsequent intramolecular cyclization, $6 \mathrm{M} \mathrm{HCl}$ was added in step $d$ after which the insoluble TPTI core unit 4 was obtained in good yield (81\%). Subsequent alkylation enabled us to purify and collect several yellow, fluorescent fractions. NMR and MALDI-TOF (SI) proved that 5 was obtained, however in moderate yield (19\%). Analysis of the other larger obtained fractions suggests that the yield in step e is limited due to the formation of several structural isomers which originates from the ambident reactivity of the amide group. After bromination of $\mathbf{5}$, the final monomer $\mathbf{6}$ was obtained which was polymerized with either 2,5bis(trimethylstannyl)thieno[3,2-b]thiophene (P1) or 2,5bis(trimethylstannyl)selenophene (P2) in high yield (>95\%).

\section{Physico-chemical properties}

We find both polymers to be only moderately soluble in orthodichlorobenzene (DCB), while chloroform (CF) and chlorobenzene (CB) permitted solutions with higher concentrations (10-20 $\left.\mathrm{g} \mathrm{L}^{-1}\right)$. The physico-chemical properties of $\mathrm{P} 1$ and $\mathrm{P} 2$ are listed in Table 1. Both polymers have comparable and limited molecular weights as determined via size-exclusion chromatography (SEC). The oxidation and reduction potentials of $\mathrm{P} 1$ and $\mathrm{P} 2$ were measured via square-wave voltammetry $((\mathrm{SWV})$, see $\mathrm{SI})$. For $\mathrm{P} 1 V_{\text {red }}^{\text {peak }}=-2.14 \mathrm{~V}$, which corresponds to an estimated LUMO value $-2.99 \mathrm{eV}$. For P2 $V_{\text {red }}^{\text {peak }}=-2.06 \mathrm{~V}$ was measured, corresponding to a LUMO energy of $-3.07 \mathrm{eV}$, indicating that the LUMO of P2 would be shifted by $\sim 0.1 \mathrm{eV}$ downwards in energy as compared to $P 1$. The first and second oxidation peaks overlap for each polymer prevents accurate determination of HOMO values, which in any case seem to be similar in energy. From UV-vis absorption spectroscopy (Fig. 1a)

Table 1 | Summary of physico-chemical properties and GIWAXS results of P1 and P2
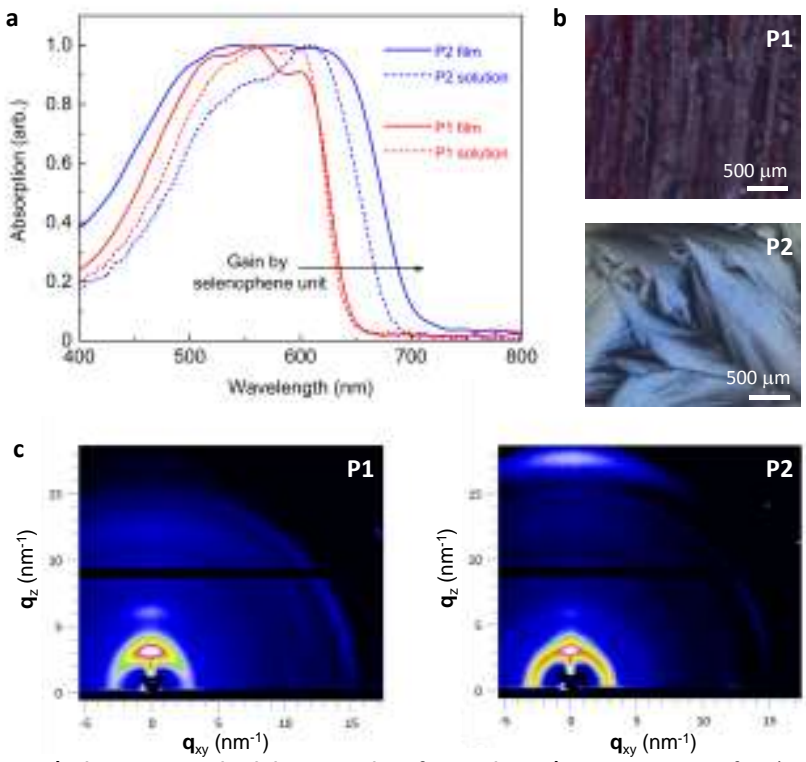

Figure 1 | Absorption and solid-state order of P1 and P2. a) UV-Vis spectra of P1 (red) and P2 (blue) in solution (dashed lines) and in films (sold lines). The gain in absorption by the use of P2 is indicated by the horizontal black arrow. b) POM images of the corresponding films suggest the ability to order for both P1 and P2. c) 2D-GIWAXS results of the corresponding pristine polymer films.

an absorption onset of $\sim 650 \mathrm{~nm}$ was determined and $E_{g}^{\text {opt }}$ $\sim 1.92 \mathrm{eV}$ for P1 and an absorption onset of $700 \mathrm{~nm}$ for P2 with a correspondingly lower bandgap of $E_{g}^{\text {opt }} \sim 1.76 \mathrm{eV}$. The advantage of incorporating the selenophene-moiety is a redshifted optical absorption in films by $\sim 0.16 \mathrm{eV}$, thereby suggesting that if the lower LUMO level of P2 does not lead to less efficient charge separation, a larger photocurrent could be extracted from photovoltaic devices based on P2. The effect of incorporating the thienothiophene moiety (P1) is opposite, i.e. its extended conjugated system reduces the electron-donating ability and blue-shifts the optical absorption. Combined with the relatively weak acceptor strength of the TPTI unit it results in reduced intra-molecular charge transfer and therefore a larger bandgap. The above results therefore suggest that OSC's based on P2 will have a similar $\mathrm{V}_{\mathrm{oc}}$ and potentially a higher short-circuit density as compared to $\mathrm{P} 1$.

Several vibronic features are visible in the solid state UV-Vis spectrum, which might suggest that both materials are ordered. Initially, we have probed solid-state order in P1 and P2 with polarized optical miscroscopy (POM) via epitaxial growth of each polymer onto the crystallizable solvent 1,3,5-

\begin{tabular}{|c|c|c|c|c|c|c|c|c|c|}
\hline Material & $\mathbf{M}_{\mathrm{n}, \mathrm{rel}^{\mathrm{a}}}$ & PDI & $V_{\text {red }}^{\text {peak }}$ & LUMO $^{b}$ & $E_{g}^{o p t}$ & $\begin{array}{l}\text { Backbone } \\
\text { orientation }\end{array}$ & $\begin{array}{l}\text { Lamellar } \\
\text { spacing }\end{array}$ & $\begin{array}{c}\text { Disordered } \\
\text { phase }\end{array}$ & $\pi$-spacing \\
\hline Units & $\mathrm{kg} \mathrm{mol}^{-1}$ & & V & $\mathrm{eV}$ & $\mathrm{eV}$ & - & $\AA$ & $\AA$ & $\AA$ \\
\hline P1 & 9.6 & 4.7 & -2.14 & -2.99 & 1.92 & $\begin{array}{c}\text { Predominantly } \\
\text { edge-on }\end{array}$ & $\sim 20.7$ & $\sim 4.1$ & $\sim 3.58$ \\
\hline P2 & 12.5 & 5.1 & -2.06 & -3.07 & 1.76 & $\begin{array}{c}\text { Face-on and } \\
\text { edge-on }\end{array}$ & 19.8 & $\sim 4.1$ & absent \\
\hline
\end{tabular}

${ }^{a}$ in $1,2,4$-trichlorobenzene $(\mathrm{TCB})$ at $150{ }^{\circ} \mathrm{C}$, relative to polystyrene standards, ${ }^{\mathrm{b}}=-V_{\text {red }}^{\text {peak }}-5.13 \mathrm{eV}$ 
trichlorobenzene. The images from POM (Fig. 1b) show that both polymer films exhibit birefringence under polarized light, indicating their ability to order. To obtain more detailed information regarding solid-state order of both polymers, we performed GIWAXS on thin films of P1 and P2 that were spincoated from a $\mathrm{CB}$ solution on silicon substrates with a native oxide layer (Fig. 1c and Table 1).

Both polymers show significant lamellar ordering, as indicated by the presence of first and second order out-of-plane diffractions. For P1 the predominant out-of-plane lamellar peaks are present at $q$ value of $3.18 \mathrm{~nm}^{-1}$ and $6.27 \mathrm{~nm}^{-1}$, corresponding to an inter-chain d spacing of $19.8 \AA$ A. For P2, the diffraction representing lamellar stacking appears at $q$ value of $3.04 \mathrm{~nm}^{-1}$ and $5.94 \mathrm{~nm}^{-1}$, corresponding to a slightly wider interchain spacing of $20.7 \AA$ (in both cases an orthorhombic unit cell is assumed). For P1, the $\pi$-stacking diffraction peak in the GIWAXS pattern is absent, possibly due to the size limitation of the detector. Conversely, a predominant out-of-plane diffraction peak at q value of $17.6 \mathrm{~nm}^{-1}$ was found in the GIWAXS pattern of P2. This peak was attributed to $\pi$-stacking with a distance of $3.58 \AA$ that, despite the strong out-of-plane lamellar diffraction, suggests that a significant population of molecules have adopted a face-on orientation with respect to the substrate, potentially arising from nucleation at the interface. ${ }^{34}$ Additionally, both polymers show a weak isotropic diffraction around $15.2 \mathrm{~nm}^{-1}(\mathrm{~d}=4.1 \AA$ ) $)$. Moreover, similar film thickness of $\mathrm{P} 1$ and $\mathrm{P} 2$ and an identical measurement setup used with the same exposure time reveals a much higher lamellar diffraction peak intensity for P1 (see SI), indicating higher solid state order for P1 compared to P2. While being less ordered than P1, the full width at half maximum (FWHM) value for $P 2$ is slightly smaller which indicates slightly larger crystallites in P2. The incorporation of the selenophene moiety thus results in face-on
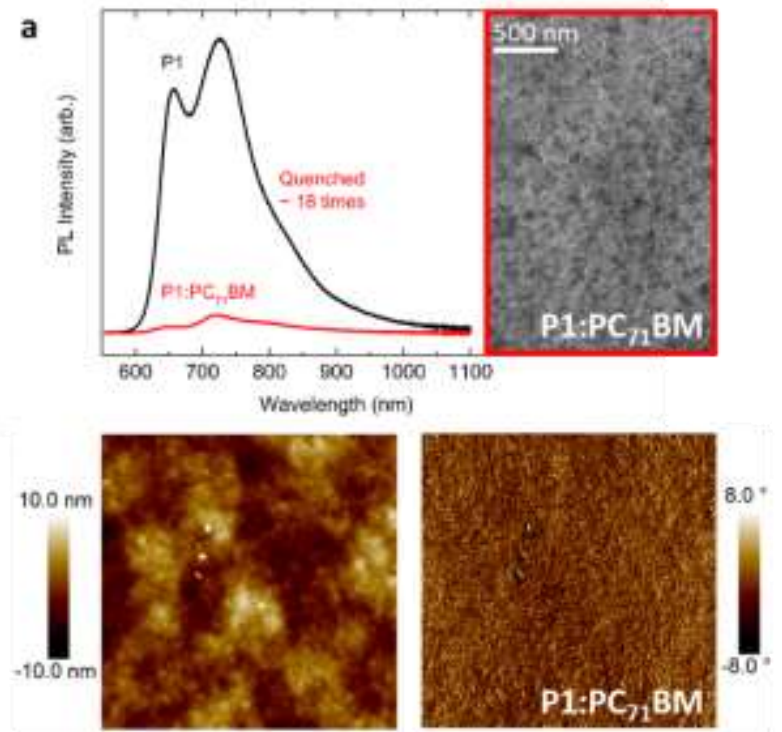

and edge-on backbone orientation in $\mathrm{P} 2$, where the face-on backbone orientation is generally indicated to improve both vertical and lateral charge transport in OSC's and, thus, $\mathrm{J}_{\mathrm{sc}}$ and FF. ${ }^{8}, 35$ In contrast, $\mathrm{P} 1$ appears to be more ordered but displays a predominantly edge-on backbone orientation, which potentially limits vertical charge transport.

\section{Photovoltaic device properties}

Photoactive blends were initially optimized in the technologically relevant inverted device geometry (ITO/PFPA$1 /$ Active Layer $/ \mathrm{MoO}_{3} / \mathrm{Ag}$ ), where charge collection polarity is reversed with respect to the conventional architecture to allow for high work-function metal electrodes such as $\mathrm{Au}$ and $\mathrm{Ag}$ to be used as hole-collecting reflective back electrodes. However, to investigate the full potential of $\mathrm{P} 1: \mathrm{PC}_{71} \mathrm{BM}$ and $\mathrm{P} 2: \mathrm{PC}_{71} \mathrm{BM}$ based devices we have also tested solar cells in the conventional, standard device geometry consisting of ITO/PEDOT:PSS/Active layer/LiF/Al, which we find currently outperforms inverted devices. Herein, we only discuss photoactive blends used in the standard device geometry. For details regarding processing, device optimization and the conventional and inverted geometries, see the supporting information

The nanostructure of $\mathrm{P} 1: \mathrm{PC}_{71} \mathrm{BM}$ and $\mathrm{P} 2: \mathrm{PC}_{71} \mathrm{BM}$ blends was investigated by photoluminescence (PL) quenching, transmission electron microscopy (TEM) (Fig. 2a+b, upper panels) and atomic force microscopy (AFM) experiments (Fig. $2 a+b$, lower panels). PL quenching experiments indicate efficient quenching in these blends: $\mathrm{PL}$ is quenched $\sim 25$ and $~$ 18 times in in $\mathrm{P} 2: \mathrm{PC}_{71} \mathrm{BM}$ and $\mathrm{P} 1: \mathrm{PC}_{71} \mathrm{BM}$ respectively, suggesting that both polymers form a fine nanostructure with $\mathrm{PC}_{71} \mathrm{BM}$ that favors charge separation and photocurrent generation. TEM imaging further corroborates formation of an
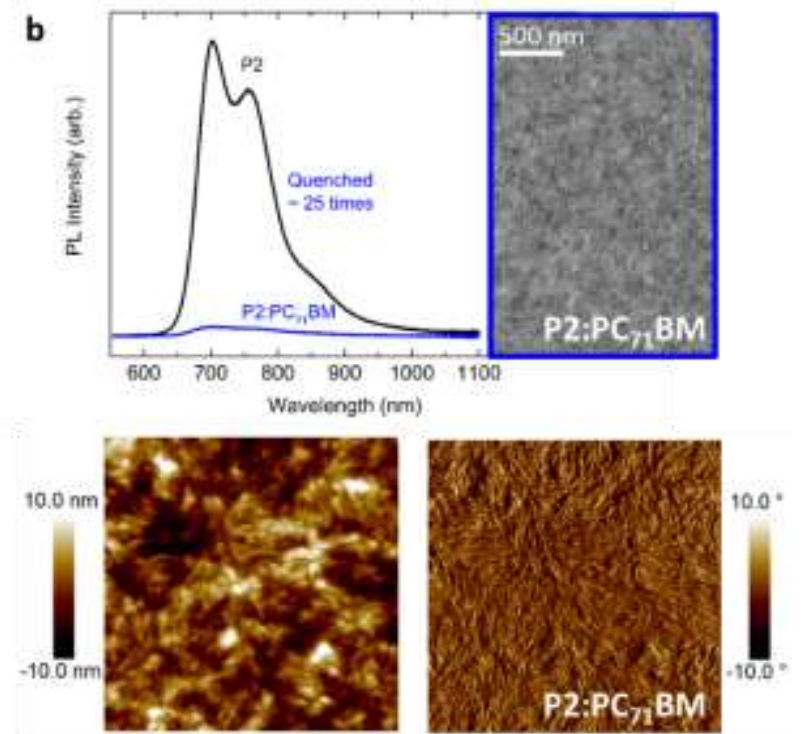

Figure 2 | Morphology studies of (a) P1:PC $\mathbf{P 1}_{71} \mathrm{BM}$ and (b) P2:PC $\mathbf{7 1}_{71} \mathrm{BM}$ photovoltaic blends. Top panel shows PL of pristine polymers (black lines) and polymer:PC ${ }_{71} \mathrm{BM}$ blends (coloured lines), indicating considerable PL quenching in the blends. The morphology of the corresponding blend films is shown by the TEM images (to the right of PL experiments), indicating a well-intermixed blend morphology. Bottom panel shows the topography and phase AFM images ( $2 \mu \mathrm{m} \times 2 \mu \mathrm{m})$ of the corresponding blend films spincoated on ITO/PEDOT:PSS as in solar cell devices. Fibril-like structure is more evidently visible in the phase image of $\mathrm{P2}: \mathrm{PC}_{71} \mathrm{BM}$. 
intimately mixed nanostructure for both active layer blends is formed. It is worth noting that both material blends need small additions (1-3\%) of the processing agent 1,8-diiodooctane (DIO) to obtain a finely intermixed nanostructure and a concomitantly high $\mathrm{J}_{\mathrm{sc}}$. AFM images of $\mathrm{P} 1: \mathrm{PC}_{71} \mathrm{BM}$ and $\mathrm{P} 2: \mathrm{PC}_{71} \mathrm{BM}$ based devices reveal smooth thin films with root-mean-square height (RMS) values of $2.3 \mathrm{~nm}$ and $3.4 \mathrm{~nm}$, respectively. The slightly increased surface roughness of $\mathrm{P} 2: \mathrm{PC}_{71} \mathrm{BM}$ blends is attributed to a pronounced fibril-like texture which is present in thin films of both the $\mathrm{P} 2: \mathrm{PC}_{71} \mathrm{BM}$ blend and pristine $\mathrm{P} 2$.

The enhanced absorption of $\mathrm{P} 2$ compared to $\mathrm{P} 1$ extrapolates to the performance of OSC's based on P2. For P1 a maximum PCE of $5.5 \%$ is achieved, while OSC's incorporating P2 as the donor material reach PCE over $7 \%$. As P1 suffers from an inherently lesser spectral coverage as compared to P2, to achieve comparable $\mathrm{J}_{\mathrm{sc}}$ in OSC's based on P1 the active layer thickness of $\mathrm{P} 1$ based devices was increased to match the $\mathrm{J}_{\mathrm{sc}}$ of $\mathrm{P} 2$ (Fig.3a). Although comparable $\mathrm{J}_{\mathrm{sc}}$ was achieved, we find that thicker P1 based OSC's suffer a loss in both FF and $V_{\text {oc}}$. We observe that if the thickness of the $\mathrm{P} 1: \mathrm{PC}_{71} \mathrm{BM}$ devices is optimized, both the $\mathrm{FF}$ and the $\mathrm{V}_{\mathrm{oc}}$ are increased and found comparable to devices based on $\mathrm{P} 2: \mathrm{PC}_{71} \mathrm{BM}$. Thus, $\mathrm{FF}$ and $\mathrm{V}_{\text {oc }}$ losses in thicker

a
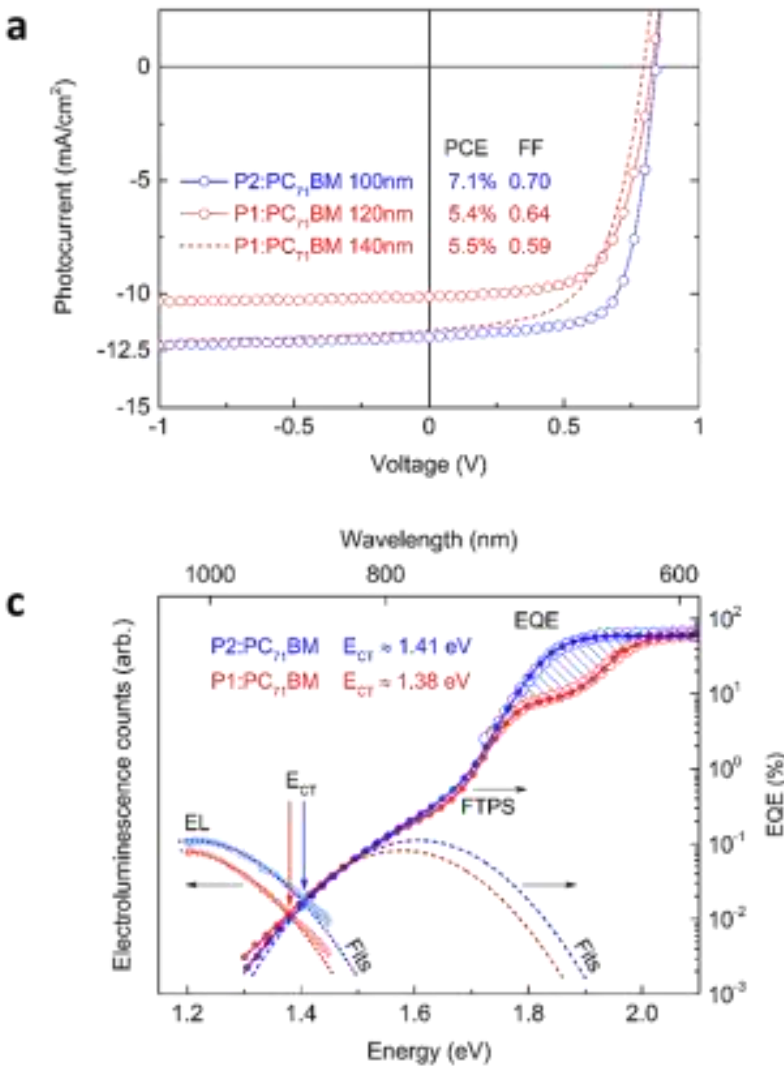

Table 2 | Photovoltaic performance of the most efficient devices

\begin{tabular}{cccccc} 
Blend & $\begin{array}{c}\text { Thickness } \\
(\mathbf{n m})\end{array}$ & $\begin{array}{c}\mathbf{J}_{\text {sc }} \\
\left(\mathbf{m A} / \mathbf{c m}^{2}\right)\end{array}$ & FF & $\begin{array}{c}\mathbf{V}_{\text {oc }} \\
(\mathbf{V})\end{array}$ & $\begin{array}{c}\text { PCE } \\
(\%)\end{array}$ \\
\hline $\begin{array}{c}\mathrm{P} 2: \\
\mathrm{PC}_{71} \mathrm{BM}\end{array}$ & $\sim 100 \mathrm{~nm}$ & 11.9 & 0.70 & 0.84 & 7.1 \\
$\begin{array}{c}\mathrm{P} 1: \\
\mathrm{PC}\end{array}$ & $\sim 120 \mathrm{~nm}$ & 10.1 & 0.64 & 0.83 & 5.4 \\
$\begin{array}{c}\mathrm{P} 1: \\
\mathrm{PC}_{71} \mathrm{BM}\end{array}$ & $\sim 140 \mathrm{~nm}$ & 11.6 & 0.59 & 0.80 & 5.5
\end{tabular}

P1:PC71BM are likely induced by a charge carrier transport limitation. ${ }^{36}$ This is supported by single-carrier diode measurements (SCLC, see $\mathrm{SI}$ ), which indicate considerably lower hole mobilities in $\mathrm{P} 1: \mathrm{PC}_{71} \mathrm{BM}$ as compared to $\mathrm{P} 2: \mathrm{PC}_{71} \mathrm{BM}$, while electron transport was found to be rather similar. We attribute the improved hole transport and, thus, $\mathrm{FF}$ in $\mathrm{P} 2: \mathrm{PC}_{71} \mathrm{BM}$ to the partly face-on backbone orientation of $\mathrm{P} 2$, as supported by the GIWAXS. Resulting OSC's based on P2 are therefore more efficient and outperform those based on $\mathrm{P} 1$, most notably due to higher $\mathrm{J}_{\text {sc. }}$. Additionally, we find the devices based on $\mathrm{P} 2$ to be

b
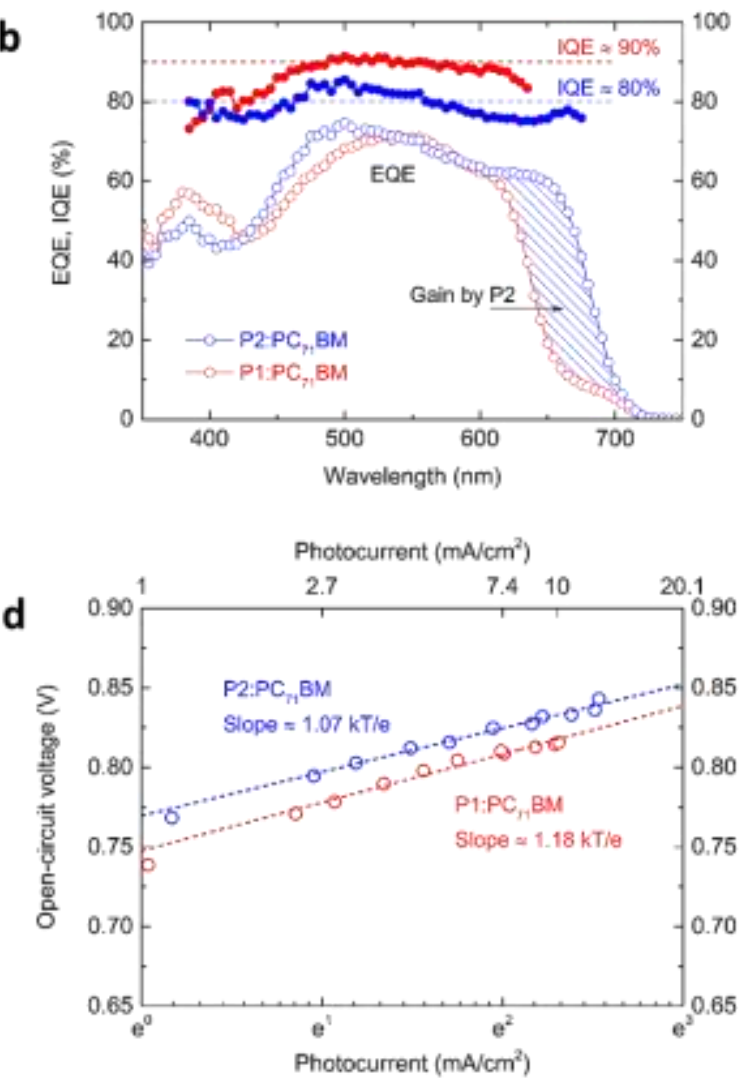

Figure 3 | Characterization of photovoltaic devices. (a) Current-voltage characteristics of $\mathrm{P} 1: \mathrm{PC} \mathrm{F}_{71} \mathrm{BM}$ (red) and $\mathrm{P2}: \mathrm{PC} \mathrm{C}_{71} \mathrm{BM}$ (blue) based photovoltaic devices. The red dashed line indicates the $\mathrm{j}-\mathrm{V}$ curve of a thicker $\mathrm{P} 1: \mathrm{PC}_{71} \mathrm{BM}$ device (b) Quantum efficiency (open circles) of the corresponding devices in panel a. The shaded area indicates the gain in photocurrent in the red-spectral region by the use of P2. Estimated IQE is indicated by the filled circles, dashed lines are a guide to the eye. (c) Charge-transfer state studies by combined FTPS (lines with circles), EQE (open circles) and EL (solid lines) experiments. The shaded area indicates the gain in photocurrent as in panel b. The energy of the chargetransfer state is indicated by the coloured arrows. The fits to FTPS and EL according to Marcus theory are the dashed and the dotted lines respectively. (d) Recombination as studied by measuring the light-intensity dependence of the open-circuit voltage, plotted against the photocurrent at $-2 \mathrm{~V}$. Open circles are the experiment, the dashed lines are fits according ref. 33. 
more reproducible compared to devices based on P1 (see SI). Table 2 summarizes device performance of the most efficient devices.

The redshifted absorption edge of P2 compared to P1 leads to an improvement in $\mathrm{J}_{\mathrm{sc}}$, as can be inspected by the EQE of the most efficient OSC's (Fig. 3b). This gain in $\mathrm{J}_{\mathrm{sc}}$ is in part due to the additional absorption of $\mathrm{P} 2$, as the absorption coefficients of the blends in the red spectral region can be scaled to the EQE measurement (see $\mathrm{SI}$ ), meaning that the absorbed photons are successfully extracted as charges. IQE measurements confirm this observation (Fig. 3b), where a relatively weakly wavelength dependent and similar IQE $~ 80-90 \%$ is observed in both blend systems. Most importantly, the gain in spectral coverage induced by the use of the selenophene unit does not lead to a loss of $\mathrm{V}_{\mathrm{oc}}$, evidenced by the similar $\mathrm{V}_{\mathrm{oc}}$ of $\mathrm{P1}: \mathrm{PC} \mathrm{C}_{71} \mathrm{BM}$ and $\mathrm{P} 2: \mathrm{PC}_{71} \mathrm{BM}$ devices.

Subsequently, we investigated why comparable $V_{o c}$ in both $\mathrm{P} 2: \mathrm{PC}_{71} \mathrm{BM}$ and $\mathrm{P} 1: \mathrm{PC} \mathrm{C}_{71} \mathrm{BM}$ devices is achieved, despite $\mathrm{a} \sim 0.15$ $\mathrm{eV}$ difference in absorption onset. A well-established empirical rule states that the $\mathrm{V}_{\text {oc }}$ of a photovoltaic blend is directly related to the energy of the charge-transfer (CT) state. ${ }^{37,} 38$ We thus expect the energy of the CT state to be similar in both blend systems. The energy of the $\mathrm{CT}$ state was estimated for each photovoltaic blend by FTPS, i.e. a sensitive measurement of the EQE (Fig. 3c). Again, the gain in EQE by the use of $P 2: P C_{71} B M$ instead of $\mathrm{P} 1: \mathrm{PC}_{71} \mathrm{BM}$ in the $1.8-2 \mathrm{eV}$ region can be observed, as indicated by the shaded area. The lower energy part of the FTPS spectra originates from an excitation in the CT manifold and can be fitted by Marcus theory to estimate the energy of the CT state. We find the estimated energy of the CT state to be similar $\sim 1.4 \mathrm{eV}$ in both blend systems, see Figure 3c. This observation is further confirmed by EL measurements (Fig. 3c), as close to identical emission is found in both blend systems. According to detailed-balance theory there is a reciprocal relation between $\mathrm{CT}$ absorption and $\mathrm{CT}$ emission, 37,38 i.e. one can be estimated from the other, as indicated by the dashed and dotted CT fit lines. Excellent agreement between scaled emission from EL measurements and CT emission, as estimated from the fit to FTPS experiments, is obtained - therefore EL emission does originate from the CT state and, thus, both blend systems have a similar CT energy. Knowledge of both the EQE from FTPS measurements and the EQE of electroluminescence $\left(E Q E_{E L}\right)$ allows us to estimate the $V_{o c}$ as outlined in refs 31 and 32. We observe similar $\mathrm{EQE}_{\mathrm{EL}} \sim 1-2 \times 10^{-5}$ values in both blend systems. Estimated radiative and non-radiative losses are $\sim 0.28$ $\mathrm{eV}$ and $\sim 0.285 \mathrm{eV}$ for $\mathrm{P} 1: \mathrm{PC}_{71} \mathrm{BM}$, and $\sim 0.295 \mathrm{eV}$ and $\sim 0.29 \mathrm{eV}$ for $\mathrm{P} 2: \mathrm{PC}_{71} \mathrm{BM}$. Subtracting these losses from the energy of the $\mathrm{CT}$ state, the resulting $\mathrm{V}_{\text {oc }}$ predictions are $\sim 0.82 \mathrm{eV}$ and $\sim 0.83$ $\mathrm{eV}$ for $\mathrm{P} 1: \mathrm{PC}_{71} \mathrm{BM}$ and $\mathrm{P} 2: \mathrm{PC}_{71} \mathrm{BM}$ respectively, in excellent agreement with the experiment in Fig. 3a. We thus conclude that the origin of the similar $V_{\text {oc }}$ in both blend systems is due to their similar energy of the $\mathrm{CT}$ state and similar radiative and non-radiative losses.

However, despite the advantages of incorporating the selenophene unit into TPTI, it might affect the dominant recombination mechanism present in the photovoltaic blend. We have thus investigated the dependence of the $V_{\text {oc }}$ on illumination intensity (Fig. 3d), i.e. a common tool to study the dominant recombination mechanism in OPV devices. A slope of $\mathrm{kT} / \mathrm{e}=1$ would indicate bimolecular recombination to be the dominant recombination mechanism, however slopes higher than $>1$ have been shown to indicate trap-assisted recombination. ${ }^{39}$ For $\mathrm{P} 2: \mathrm{PC}_{71} \mathrm{BM}$ we observe a slope close to 1 , indicating bimolecular recombination to be the dominant recombination mechanism, however a higher slope for $\mathrm{P} 1: \mathrm{PC} \mathrm{71}_{11} \mathrm{BM}$ is observed. Note that it does not lead to significant photocurrent losses as device J-V curves are largely fieldindependent at reverse bias (Fig. 3a), however it might affect extraction closer to $\mathrm{V}_{\mathrm{oc}}$ and thus the FF of the operating OSC. Finally, we point out that in ref. 25 a higher FF was observed in devices based on $\mathrm{P} 1: \mathrm{PC}_{71} \mathrm{BM}$ than we report here. We propose that the reduced $\mathrm{FF}$ in our case originates from the relatively low-molecular weight of P1 ( $\mathrm{M}_{\mathrm{n}}$ : 9.8 KDa, PDI: 4.7) compared to the previously reported $P 1$ backbone $\left(M_{n}: 20.6 \mathrm{KDa}, \mathrm{PDI}: 1.98\right)$, which can be readily explained by our use of slightly shorter alkyl side chains (2-hexyldecyl vs. 2-octyldodecyl). Therefore, a higher $\mathrm{J}_{\mathrm{sc}}$ (via a higher IQE) and a higher FF (via better transport and/or less traps) may be achieved in the future by optimizing the molecular weight and/or processing conditions of P2.

\section{Conclusions}

We have developed a new synthetic route for the pentacyclic lactam TPTI unit. Via polymerization with either thienothiophene or selenophene we obtained two TPTI donor copolymers, of which the selenophene derivative offers a combination of deep HOMO and redshifted optical absorption. Additionally, via GIWAXS we find a difference in the solid-state microstructure of each polymer; both edge-and face-on backbone orientations for the selenophene derivative, while the thienothienophene derivative showed only edge-on backbone orientation with respect to the substrate. AFM, TEM and PL-quenching experiments indicate similar blend nanostructures, while analysis of Fourier-transform photocurrent spectroscopy and electroluminescence data indicate virtually the same CT-energy and energy losses, which is the origin of the similar $\mathrm{V}_{o c}$ in both blend systems. SCLC revealed improved hole transport in photovoltaic blends based on the selenophene derivative which was attributed to its partly face-on backbone orientation, as supported by GIWAXS. We therefore conclude that the improved photovoltaic performance of $\mathrm{BHJ}$ OSC based on the selenophene derivative is due to the partial face-on backbone orientation and improved spectral coverage, leading to a promising PCE of $7.1 \%$ with potential for improvement.

\section{Acknowledgements}

We thank the Chalmers Areas of Advance Materials Science, Energy and Nanoscience and Nanotechnology as well as the Swedish Research Council, the Knut and Alice Wallenberg foundation through a Wallenberg Scholar grant to OI, Formas for funding. O.I., R.K. and M.R.A. further acknowledge the 
Swedish Energy Agency and R.K and M.R.A. the South Australian government for financial support. A.A. acknowledges SABIC for the Career Development SABIC Chair. Part of this work was done at the Cornell High Energy Synchrotron Source (CHESS), supported by the NSF \& NIH/NIGMS via NSF award DMR1332208

\section{Notes and references}

1. N. Espinosa, M. Hosel, D. Angmo and F. C. Krebs, Energy \& Environmental Science, 2012, 5, 5117-5132.

2. J. You, C.-C. Chen, Z. Hong, K. Yoshimura, K. Ohya, R. Xu, S. Ye, J. Gao, G. Li and Y. Yang, Advanced Materials, 2013, 25, 3973-3978.

3. Y. Jingbi, D. Letian, Y. Ken, K. Takehito, O. Kenichiro, M. Tom, E. Keith, C. Chun-Chao, G. Jing, L. Gang and Y. Yang, Nature Communications, 2013, 4, 1446-1446.

$4 . \quad$ Z. He, B. Xiao, F. Liu, H. Wu, Y. Yang, S. Xiao, C. Wang, T. P. Russell and Y. Cao, Nat Photon, 2015, 9, 174-179.

$5 . \quad$ L. K. Jagadamma, M. Al-Senani, A. El-Labban, I. Gereige, G. O. Ngongang Ndjawa, J. C. D. Faria, T. Kim, K. Zhao, F. Cruciani, D. H. Anjum, M. A. McLachlan, P. M. Beaujuge and A. Amassian, Advanced Energy Materials, 2015, 5, n/a-n/a.

6. R. R. Søndergaard, M. Hösel and F. C. Krebs, Journal of Polymer Science Part B: Polymer Physics, 2013, 51, 16-34.

7. C. H. Peters, I. T. Sachs-Quintana, J. P. Kastrop, S. Beaupré, M. Leclerc and M. D. McGehee, Advanced Energy Materials, 2011, 1, 491-494.

8. X. Zhang, L. J. Richter, D. M. DeLongchamp, R. J. Kline, M. R. Hammond, I. McCulloch, M. Heeney, R. S. Ashraf, J. N. Smith, T. D. Anthopoulos, B. Schroeder, Y. H. Geerts, D. A. Fischer and M. F. Toney, Journal of the American Chemical Society, 2011, 133, 15073-15084.

9. H. Bronstein, Z. Chen, R. S. Ashraf, W. Zhang, J. Du, J. R. Durrant, P. Shakya Tuladhar, K. Song, S. E. Watkins, Y. Geerts, M. M. Wienk, R. A. J. Janssen, T. Anthopoulos, H. Sirringhaus, M. Heeney and I. McCulloch, Journal of the American Chemical Society, 2011, 133, 3272-3275.

10. Z. Chen, Y. Zheng, H. Yan and A. Facchetti, Journal of the American Chemical Society, 2008, 131, 8-9.

11. W. Zhang, J. Smith, S. E. Watkins, R. Gysel, M. McGehee, A. Salleo, J. Kirkpatrick, S. Ashraf, T. Anthopoulos, M. Heeney and I. McCulloch, Journal of the American Chemical Society, 2010, 132, 11437-11439.

12. J. E. Donaghey, E.-H. Sohn, R. S. Ashraf, T. D. Anthopoulos, S. E. Watkins, K. Song, C. K. Williams and I. McCulloch, Polymer Chemistry, 2013, 4, 3537-3544.

13. B. C. Schroeder, Z. Huang, R. S. Ashraf, J. Smith, P. D'Angelo, S. E. Watkins, T. D. Anthopoulos, J. R. Durrant and I. McCulloch, Advanced Functional Materials, 2012, 22, 1663-1670.

$14 . \quad$ C.-P. Chen, S.-H. Chan, T.-C. Chao, C. Ting and B.-T. Ko, Journal of the American Chemical Society, 2008, 130, 12828-12833.

15. Q. Zheng, B. J. Jung, J. Sun and H. E. Katz, Journal of the American Chemical Society, 2010, 132, 5394-5404.

16. L. Biniek, B. C. Schroeder, J. E. Donaghey, N. YaacobiGross, R. S. Ashraf, Y. W. Soon, C. B. Nielsen, J. R. Durrant, T. D. Anthopoulos and I. McCulloch, Macromolecules, 2013, 46, 727-735.
17. Y.-X. Xu, C.-C. Chueh, H.-L. Yip, F.-Z. Ding, Y.-X. Li, C.-Z. Li, X. Li, W.-C. Chen and A. K. Y. Jen, Advanced Materials, 2012, 24, 6356-6361.

18. C.-Y. Chang, Y.-J. Cheng, S.-H. Hung, J.-S. Wu, W.-S. Kao, C.-H. Lee and C.-S. Hsu, Advanced Materials, 2012, 24, 549-553.

19. R. Kroon, A. Diaz de Zerio Mendaza, S. Himmelberger, J. Bergqvist, O. Bäcke, G. C. Faria, F. Gao, A. Obaid, W. Zhuang, D. Gedefaw, E. Olsson, O. Inganäs, A. Salleo, C. Müller and M. R. Andersson, Journal of the American Chemical Society, 2014, 136, 11578-11581.

20. C. Schwarz, H. Bässler, I. Bauer, J.-M. Koenen, E. Preis, U. Scherf and A. Köhler, Advanced Materials, 2010, 24, 922 925.

21. S. Shoaee, M. P. Eng, E. Espildora, J. L. Delgado, B. Campo, N. Martin, D. Vanderzande and J. R. Durrant, Energy \& Environmental Science, 2010, 3, 971-976.

22. D. Veldman, S. C. J. Meskers and R. A. J. Janssen, Advanced Functional Materials, 2009, 19, 1939-1948.

23. S. Westenhoff, I. A. Howard, J. M. Hodgkiss, K. R. Kirov, H. A. Bronstein, C. K. Williams, N. C. Greenham and R. H. Friend, Journal of the American Chemical Society, 2008, 130, 13653-13658.

24. J. Cao, Q. Liao, X. Du, J. Chen, Z. Xiao, Q. Zuo and L. Ding, Energy \& Environmental Science, 2013, 6, 3224-3228.

25. C. Zuo, J. Cao and L. Ding, Macromolecular Rapid Communications, 2014, 35, 1362-1366.

26. Q. Liao, J. Cao, Z. Xiao, J. Liao and L. Ding, Physical Chemistry Chemical Physics, 2013, 15, 19990-19993.

27. A. M. Ballantyne, L. Chen, J. Nelson, D. D. C. Bradley, Y. Astuti, A. Maurano, C. G. Shuttle, J. R. Durrant, M. Heeney, W. Duffy and I. McCulloch, Advanced Materials, 2007, 19, 4544-4547.

28. W. Zhuang, H. Zhen, R. Kroon, Z. Tang, S. Hellstrom, L. Hou, E. Wang, D. Gedefaw, O. Inganas, F. Zhang and M. R. Andersson, Journal of Materials Chemistry A, 2013, 1, 13422-13425.

$29 . \quad$ L. Dou, W.-H. Chang, J. Gao, C.-C. Chen, J. You and Y. Yang Advanced Materials, 2013, 25, 825-831.

30. H. A. Saadeh, L. Lu, F. He, J. E. Bullock, W. Wang, B. Carsten and L. Yu, ACS Macro Letters, 2012, 1, 361-365.

31. J. Cao, C. Zuo, B. Du, X. Qiu and L. Ding, Chemical Communications, 2015, 51, 12122-12125.

32. J. Cao, S. Chen, Z. Qi, Z. Xiao, J. Wang and L. Ding, RSC Advances, 2014, 4, 5085-5087.

33. J. M. Tour and J. J. S. Lamba, Journal of the American Chemical Society, 1993, 115, 4935-4936.

34. L. H. Jimison, S. Himmelberger, D. T. Duong, J. Rivnay, M. F. Toney and A. Salleo, Journal of Polymer Science Part B: Polymer Physics, 2013, 51, 611-620.

35. E. D. Gomez, K. P. Barteau, H. Wang, M. F. Toney and Y.-L. Loo, Chemical Communications, 2011, 47, 436-438.

36. J. A. Bartelt, D. Lam, T. M. Burke, S. M. Sweetnam and M. D. McGehee, Advanced Energy Materials, 2015, n/a-n/a.

37. K. Vandewal, K. Tvingstedt, A. Gadisa, O. Inganäs and J. V. Manca, Physical Review B, 2010, 81, 125204.

38. K. Vandewal, K. Tvingstedt, J. V. Manca, Ingana, $x$ and O. s, Selected Topics in Quantum Electronics, IEEE Journal of, 2010, 16, 1676-1684.

39. M. M. Mandoc, F. B. Kooistra, J. C. Hummelen, B. de Boer and P. W. M. Blom, Applied Physics Letters, 2007, 91, 263505. 
